\title{
Avaliação Sensorial de Bebida Proteica com Adição da Microalga Spirulina Platensis
}

\author{
Elaine S. P. Barbosa, Karolline F. Siqueira, Patrícia L. D. Moura \& \\ Flávia I. R. O. Araújo
}

O presente trabalho objetivou desenvolver e avaliar a aceitação de uma bebida proteica com adição da microalga Spirulina platensis. Nos resultados da escala hedônica, obtiveram-se escores acima de 7 (gostei regularmente) para todos os atributos avaliados. Quanto ao aroma de limão, a bebida deve ser reformulada, diminuindo-se a sua concentração; o gosto doce está com doçura ideal para o consumo; e, 86,4\% dos provadores consumiriam o produto, frequentemente, indicando que o produto poderá ter uma boa aceitação no mercado.

Palavras chave: inovação; teste de aceitação; bebidas vegetais proteicas.

This study aimed to develop and evaluate the acceptance of a protein drink with addition of micro alga Spirulina platensis. The results of the hedonic scale was obtained scores above 7 (like regularly) for all attributes. As for the lemon flavor drink should be changed by decreasing its concentration; the sweet taste is ideal with sweet for consumption; and, $86,4 \%$ of testers often consume the product, indicating that the product may have good market acceptance.

Keywords: innovation; acceptance test; vegetable protein drinks. 


\section{Introdução}

Nos últimos anos, tem-se verificado um interesse crescente dos consumidores por alimentos que, além da função básica de nutrir, promovam efeitos benéficos à saúde ${ }^{1}$. As tendências globais apontam um crescimento do mercado em altas taxas, pela conquista natural de novos adeptos a estes alimentos, pelo surgimento quase diário de boas notícias provenientes das pesquisas científicas relacionando os alimentos funcionais à saúde e qualidade de vida, além da introdução de novos produtos no mercado, o que amplia as alternativas mercadológicas ${ }^{2}$.

As características químicas e nutricionais da soja e seus subprodutos qualificam-na também como um alimento funcional. Além da qualidade de sua proteína, estudos mostram que a soja pode ser utilizada de forma preventiva e terapêutica no tratamento de doenças cardiovasculares, câncer e osteoporose ${ }^{3}$.

Nutricionalmente, o extrato de soja apresenta $17,7 \%$ de lipídios, 33\% de proteínas, $41,4 \%$ de carboidratos e $2,4 \%$ de cinzas (em base seca) ${ }^{4}$. Tem-se, também, o isolado proteico de soja que contém pelo menos $90 \%$ de proteína, apresentando como principais componentes as frações glicinina e $\beta$-conglicinina, sendo livre de lipídios e carboidratos ${ }^{5}$. Inúmeras tecnologias têm mostrado êxito na obtenção de extratos com melhores características sensoriais, porém foi constatado que sua aceitação é aumentada quando associados a aditivos, ingredientes ou a outra matéria-prima que confira características de sabor e aroma diferentes daqueles inerentes ao extrato de soja puro ${ }^{6}$. Além de promover o aumento da digestibilidade de sua proteína, bem como inativa os inibidores de proteases e outros fatores antinutricionais, embora possa ocorrer atividade residual significativa de inibidores de proteases em produtos da soja, após tratamento térmico ${ }^{7}$.

A polidextrose é um polissacarídeo sintetizado pela polimerização randômica da glicose e pode ser considerado como alimento funcional, pois é parcialmente fermentado no intestino grosso, mas não é digerido nem absorvido no intestino delgado e, em sua maior parte, é excretado nas fezes ${ }^{8,9}$. Além disso, este polímero é extremamente estável, incolor e não apresenta sabor residual, sendo também altamente estável dentro de uma faixa ampla de $\mathrm{pH}$, temperatura, condições de processamento e estocagem ${ }^{10}$. É tolerada uma média de $90 \mathrm{~g}$ por dia, sem efeitos laxativos ${ }^{11}$. Segundo Jie et al. ${ }^{10}$ a polidextrose pode ser também considerada como pré-biótico, pois estimula o crescimento de lactobacilos e bifidobactérias e a fermentação contínua ao longo do cólon.

O colágeno é uma proteína encontrada no tecido conjuntivo, ocorrendo em tendões, cartilagens, na matriz orgânica dos ossos e na camada córnea dos olhos, conferindo resistência e/ou elasticidade a essas estruturas. Do ponto de vista nutricional, o colágeno é considerado uma proteína de qualidade inferior uma vez que quase todos os aminoácidos essenciais ou são subrepresentados, ou, no caso da cisteína, completamente ausente. Estudos têm sido realizados em humanos com resultados positivos, especialmente relacionados com a capacidade demonstrada pelo colágeno e gelatina hidrolisados em melhorar as condições das articulações, na prevenção e tratamento da osteoartrite e da osteoporose $12,13,14,15$.

Pesquisas inovadoras envolvendo a biotecnologia, por meio da utilização de micro-organismos ou enzimas para a produção de novos produtos, inclusive alimentos, estão instigando a sociedade moderna ${ }^{16}$. A aceitabilidade de um micro-organismo, em especial para o uso na alimentação humana e animal, depende de seu valor nutricional e segurança o que inclui o baixo teor de ácidos nucleicos, ausência de toxinas e de compostos residuais indesejáveis ${ }^{17}$.Várias espécies de microalgas são cultivadas comercialmente em alguns países e a biomassa produzida tem sido utilizada como fonte de produtos para aplicação na indústria de alimentos ${ }^{18}$. Segundo Pulz e Gross ${ }^{19}$, o mercado de alimentos funcionais, utilizando microalgas em massas, pães, iogurtes e bebidas, apresenta rápido desenvolvimento em vários países, como França, Estados Unidos, China e Tailândia.

ASpirulina platensis é uma microalga com composição apropriada para uso como complemento alimentar destacando-se pelo seu alto teor de cianocobalamina (vitamina B12), difícil de ser encontrada em dietas vegetarianas; pelo ácido fólico (vitamina B9), necessário para a formação das células e para o bom funcionamento dos sistemas cardiovascular e nervoso; além de seu aporte de minerais ( $\mathrm{Zn}, \mathrm{Mg}, \mathrm{Cr}, \mathrm{Se}, \mathrm{Fe}$ ) que são necessários para a manutenção do metabolismo, para a conservação 
da pele e das mucosas e para o desenvolvimento normal dos ossos e dos dentes ${ }^{20,21}$. Em sua composição em base seca, destacam-se os altos teores de proteínas $(64-74$ $\%$, ácidos graxos poli-insaturados, além de compostos antioxidantes ${ }^{22,23}$.

A Spirulina está legalmente autorizada como alimento ou complemento alimentar na Europa, Japão e costa asiática do Pacífico. No Brasil, de acordo com a VII lista dos novos ingredientes aprovados pelas Comissões Técnico-Científicas de Assessoramento em Alimentos Funcionais e Novos Alimentos (CTCAF), a ANVISA (Agência Nacional de Vigilância Sanitária) permite a comercialização da Spirulina, desde que o produto final ao qual o micro-organismo tenha sido adicionado seja devidamente registrado e não tenha alegações terapêuticas. É comercializada em forma de comprimidos, cápsulas e em pó como suplementos alimentares para o público que praticam esportes regularmente e pessoas que buscam hábito saudável de vida ${ }^{24}$.

O desenvolvimento de produtos está em estreita relação com as necessidades e tendências ou modas de consumo da massa consumidora, o que traz como consequência a necessidade de respostas rápidas das indústrias de alimentos às mudanças do mercado consumidor. A determinação da aceitação pelo consumidor é parte crucial no processo de desenvolvimento ou melhoramento de produtos. Os testes de aceitação ou afetivos podem ser empregados para avaliar a aceitação de produtos no início de seu desenvolvimento ou quando ocorre alteração na formulação, modificação nos processos, materiais, embalagens condições de estocagem ou no tempo de conservação dos alimentos ${ }^{25}$.

O presente trabalho teve como objetivo desenvolver e avaliar a aceitação de uma bebida proteica com adição da microalga Spirulina.

\section{Materiais e Métodos}

\section{MATERIAIS}

A Spirulina foi adquirida em uma fazenda de microalgas, empresa Brasil Vital, localizada na zona rural de Anápolis-GO. A legislação RDC/ANVISA n ${ }^{\circ}$ 16/1999 recomenda que o consumo diário do produto não deve resultar na ingestão de Spirulina acima de $1,6 \mathrm{~g}$. Foram utilizados os seguintes ingredientes para a formulação mistura em pó: fonte de fibra a polidextrose, proteína concentrada de soja, colágeno hidrolizado, extrato micronizado de soja e, os aditivos: aroma idêntico ao natural de limão; goma xantana; sucralose e mix de vitaminas e minerais.

\section{MÉTODOS}

\section{Elaboração das amostras}

As amostras foram preparadas na Planta de Desenvolvimento de Alimentos do Instituto SENAI de Tecnologia (IST) de Alimentos e Bebidas. A quantidade dos ingredientes para preparo da amostra está apresentada na Tabela 1. Todas as matérias-primas foram pesadas e, em seguida, misturadas em homogeneizador $\mathrm{Y}$ de modelo TE-201/10, por 10 minutos. Posteriormente, foram armazenadas em embalagem BOPP metalizado (polipropileno biorientado).

Tabela 1. Ingredientes secos utilizados na formulação da mistura em pó para bebida proteica.

\begin{tabular}{|c|}
\hline Matéria prima \\
\hline Colágeno hidrolizado \\
\hline Spirulina \\
\hline Extrato micronizado de soja \\
\hline Proteína concentrada de soja \\
\hline Polidextrose \\
\hline Aroma \\
\hline Sucralose \\
\hline Goma xantana \\
\hline Blend de vitaminas e minerais \\
\hline
\end{tabular}

\section{Análise de proteínas}

As amostras foram avaliadas, em triplicata, quanto ao teor de proteínas utilizando-se o procedimento do Instituto Adolfo Lutz (2008) ${ }^{26}$.

\section{Análise sensorial - teste de aceitação}

Os consumidores avaliaram a aceitação global das formulações, utilizando a escala hedônica de nove pontos; a frequência em que está disposto a consumir o produto em determinado período, utilizando escala de atitude de 9 pontos; e, a intensidade do aroma e gosto doce considerado 
ideal utilizando-se escala de 5 pontos ${ }^{27}$. $\mathrm{O}$ teste foi realizado em uma academia da região central da cidade de Goiânia$\mathrm{GO}$, onde as amostras de bebida proteica foram avaliadas, na mesma seção, por cada consumidor. As amostras foram servidas em copos descartáveis de $50 \mathrm{~mL}$ (temperatura aproximadamente de $12^{\circ} \mathrm{C}$ ).

\section{Análise dos resultados}

Os dados, obtidos por meio da ficha de avaliação (Figura 1), foram analisados por médias e distribuição de frequências utilizando histogramas por meio do programa Excel®.

\section{Resultados E Discussão}

De acordo com a análise laboratorial, o conteúdo de proteínas resultou em 64,20 g.100 g-1 na bebida com adição de Spirulina platensis. Os testes sensoriais foram realizados no mesmo dia do processamento da mistura em pó para evitar que os resultados sofressem influência negativa durante a vida de prateleira. Todos os testes foram realizados com provadores não-treinados. A avaliação sensorial foi realizada por uma equipe de 25 pessoas (17 mulheres e 8 homens) composta por praticantes de atividade física, não familiarizados com testes sensoriais e idades entre 16 e 60 anos, representativos do público consumidor.

Nome:

Sexo: ( ) F ( )M

Data:

I

I. Você está recebendo amostra de bebida funcional. Através da escala expresse o quanto você gostou e desgostou dos atributos sensoriais.

\begin{tabular}{l|l}
\hline (9) Gostei muitíssimo & Aparência: \\
(8) Gostei moderadamente & Cor: \\
(7) Gostei regularmente & \\
(6) Gostei ligeiramente & Aroma: \\
(5) Não gostei, nem desgostei & Sabor: \\
(4) Desgostei ligeiramente & \\
(3) Desgostei regularmente & Impressão global: \\
(2) Desgostei moderamente & (1) Desgostei muitíssimo
\end{tabular}

II. Prove a amostra novamente e através da escala abaixo marque o quão ideal se encontra AROMA da bebida funcional.

(7) aroma muito mais intenso que eu gosto

(6) aroma razoavelmente mais intenso que eu gosto

(5) aroma levemente mais intenso que eu gosto

(4) do jeito que gosto

(3) aroma levemente mais fraco que eu gosto

(2) aroma razoavelmente mais fraco que eu gosto

(1) aroma muito mais fraco que eu gosto.

III. Prove a amostra novamente e através da escala ao lado, marque o quão ideal se encontra o GOSTO DOCE da bebida.

(7) gosto doce muito mais intenso que eu gosto

(6) gosto doce razoavelmente mais intenso que eu gosto

(5) gosto doce levemente mais intenso que eu gosto

(4) do jeito que gosto

(3) gosto doce levemente mais fraco que eu gosto

(2) gosto doce razoavelmente mais fraco que eu gosto

(1) gosto doce muito mais fraco que eu gosto

IV. Marque a resposta que melhor expresse o seu julgamento:

(9) Beberia isso sempre que tivesse oportunidade.

(8) Beberia isso muito frequentemente.

(7) Beberia isso frequentemente.

(6) Gosto disso e beberia de vez em quando.

(5) Beberia isto se tivesse acessível, mas não me esforçaria para isso.

(4) Não gosto disso, mas beberia ocasionalmente.

(3) Raramente beberia isso.

(2) Só beberia isso se não pudesse escolher outro alimento.

(1) Só beberia isso se fosse forçado(a).

Figura 1. Ficha de respostas utilizando escalas hedônica, do ideal e atitude. 
A bebida proteica não apresentou média abaixo de 4 (limite inferior de aceitação), alocou-se entre as categorias "gostei moderadamente" e "gostei regularmente" para todos os atributos avaliados (Figura 2). Alguns consumidores associaram a cor verde com sucos de folhosas e, gosto amargo imperceptível comparando aos outros produtos rico em proteínas.

Em relação ao aroma da bebida proteica, observase no histograma (Figura 3) que $40 \%$ dos provadores acharam o aroma de limão mais intenso do que gostam, considerando-se que $24 \%$ acharam o aroma muito mais intenso do que gostam e, $40 \%$ a intensidade do aroma está do jeito que gosta. Portanto, a bebida deve ser reformulada, diminuindo-se a concentração do aroma de limão.

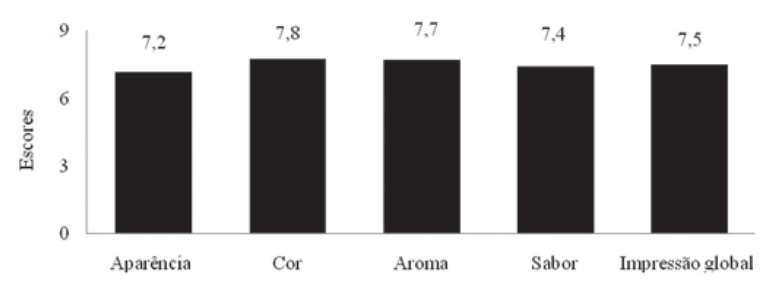

Figura 2. Escores em relação aos atributos sensoriais de bebida proteica com adição da microalga Spirulina.

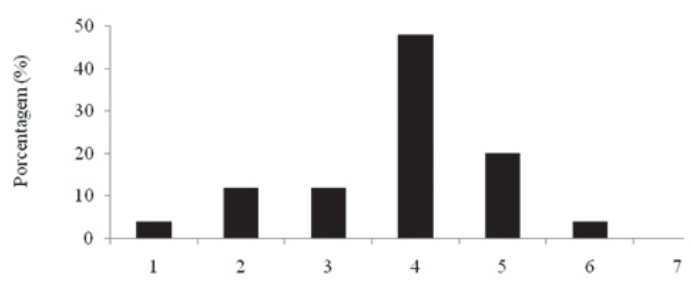

Figura 3. Porcentagem das respostas dos consumidores em cada categoria para ideal do gosto doce da bebida proteica com adição da microalga Spirulina.

Quanto ao gosto doce da bebida proteica (Figura 3), $24 \%$ dos provadores acharam o gosto mais intenso do que gosta, considerando-se que $20 \%$ acharam o gosto razoavelmente mais intenso do que gosta e, $48 \%$ o gosto está do jeito que gosta. Com relação a este quesito, a bebida está com doçura ideal para o consumo.
$\mathrm{Na}$ atitude de compra os provadores (Figura 4) 86,4\% consumiriam o produto frequentemente, indicando que o produto poderá ter uma boa aceitação no mercado, apresentando elevado consumo, sendo que apenas 4,5\% não esforçariam para comprar esta bebida. Neste último caso, os provadores podem não conhecer a microalga Spirulina ou não são consumidores de produtos proteicos. Alguns consumidores não treinados alegaram que o sabor característico é suave, a cor verde remete aos sucos caseiros naturais provenientes de folhosas (couve, agrião, entre outros) e, ainda, há partículas residuais na boca. Um dos desafios de melhoria tecnológica para uso da microalga em bebidas proteicas é diminuir as partículas da microalga e, assim, contribuir para melhor dispersão em água.

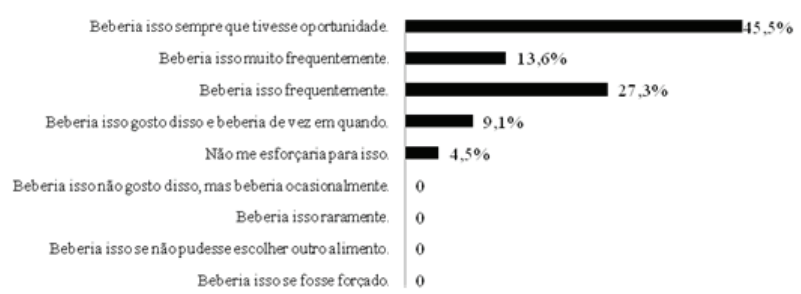

Figura 4. Porcentagem de aceitação da bebida proteica com adição da microalga Spirulina utilizando escala de atitude.

\section{Conclusão}

Este projeto apresentou a potencialidade da microalga Spirulina platensis como matéria-prima de produto industrializado. É um produto que não apresenta risco algum para o consumo humano, tem potencial valor comercial, nutricional e tecnológico. Há necessidade de mais estudos no desenvolvimento de produtos alimentícios com adição dessa microalga, principalmente, na melhoria do flavor.

\section{Referências}

1. Prates, J. A. M.; Mateus, C. M. R. Rev. Portuguesa de Ciências Veterinárias, 2002, 3-12.

2. Gazzoni, D. L. Alimentos Funcionais. Disponível em: $<$ http:// www.gazzoni.pop.com.br/alimentos_funcionais.htm $>$. Acesso em: 12 nov. 2015. 
3. Souza, G.; Valle, J. L. E.; Moreno, I. Bol. SBCTA, 2000, 61-69.

4. Bowles, S.; Demiate, I.M. Ciência e Tecnologia de Alimentos, 2006, 652-659.

5. Singh, M.; Mohamed, A. Food Science and Technology, 2005.

6. Rodrigues, R. S. Caracterização de extratos de soja obtidos de grãos, farinha integral e isolado proteico visando formulação e avaliação biológica (em coelhos) de bebida funcional a base de extrato de soja e polpa de pêssegos. Campinas, 2003. 177 p. Tese (Doutorado) - Faculdade de Engenharia de Alimentos, Universidade Estadual de Campinas.

7. Bayram, M.; Kaya, A.; Öner, M. D. Journal of Food Engineering, 2004, 221-230.

8. Stumm, I.; Batles, W. Food Chemistry, 1997, 291-297.

9. Pfizer Inc. Polidextrose food additive petition. 1978.

10. JIE, Z. et al. American Journal of Clinical Nutrition, 2000, 15031509.

11. Fakhouri, F. M. Et Al. Simpósio Latino-Americano De Ciência De Alimentos, Slaca, $6^{\circ}$, Campinas, Anais... Campinas, 2005. (CD Rom).

12. Gómez-Guillén, M.C. et al. Food Hydrocolloids, 2011, 18131827.

13. Moskowitz, R. W. Seminars in Arthrites and Rheumatism, 2000, 87-99.

14. Oesser, S. et al. Journal of Nutrition, 1999, 1891-1895.

15. Lehninger, A. L.; NELSON, D. L.; Cox, M. M.. Princípios de bioquímica. 1995.

16. Muliterno, A.; Mosele, P. C.; Costa, J. A. V.; Hemkemeier, M.; Bertolin, T. E.. Colla; L. M.. Ciênc. Agrotec., 2005, 1132-1138.

17. Bekatorou, A.; Koutinas, A. A.; Kaliafas, A.; Kanellaki, M.. Process Biochemistry, 2001, 549-557.

18. Derner, R. B.; Ohse, S.; Villela, M.; Carvalho, S. M.; FETT, R. Ciência Rural, 2006, 1959-1967.

19. Pulz, O.; Gross, W. Applied Microbiology Biotechnology, 2004, 635-648.

20. Brown, M. R.; Mular, M.; Miller, I.; Farmer, C.; Trenerry, C. Journal of Apllied Phycology, 1999, 247 - 255.

21. Becker, W. In: Richmond, A. (ed.) Handbook of Microalgal Culture: 2004, 312 - 351.

22. Cohen, Z. In: Vonshak, A. Cell-Biology and Biotechnology, 1997.

23. Colla, L. M.; Reinehr, C. O.; Reichert, C.; Costa, J. A. V. Bioresource Technology, 2007, 1489 - 1493.

24. Brasil. Agência Nacional de Vigilância Sanitária. Resolução n. 16, de 30 de abril de 1999. Diário Oficial da União, 1999.

25. Chaves, J.B.P; Sproesser, R.L. Práticas de laboratório de análise sensorial de limentos. 1999.
26. Zenebon, O.; Pascuet, N. S.; Tiglea, P. Instituto Adolfo Lutz, 2008 .

27. Minim, V. P. R.. Análise sensorial: estudos com consumidores. 2006.

\section{Elaine S. P. Barbosa*, Karolline F. Siqueira, Patrícia L. D. Moura \& Flávia I. R. O. Araújo}

1 Instituto SENAI de Tecnologia em Alimentos e Bebidas,-- Rua Professor Lázaro Costa n 348, Vila Canaã, CEP: 74415-420, Goiânia, Goiás, Brasil. Telefone: (62 3235 8159)

*E-mail: elaine.spb@gmail.com 